\title{
Determination of Integrated Molar Absorption Coefficients for Gaseous Phenol Infrared Bands and Influence of Water Vapor on Their Values
}

\author{
Thomas Onfroy ${ }^{1,2^{*}}$, Olivier Marie ${ }^{1}$ \\ ${ }^{1}$ Laboratoire Catalyse et Spectrochimie, Normandie Université/UNICAEN/ENSICAEN/CNRS, Caen, France \\ ${ }^{2}$ Sorbonne Université, CNRS, Laboratoire de Réactivité de Surface, LRS, Campus Pierre et Marie-Curie, Paris, France \\ Email: *thomas.onfroy@upmc.fr
}

How to cite this paper: Onfroy, T. and Marie, O. (2019) Determination of Integrated Molar Absorption Coefficients for Gaseous Phenol Infrared Bands and Influence of Water Vapor on Their Values. American Journal of Analytical Chemistry, 10, 9-22.

https://doi.org/10.4236/ajac.2019.101002

Received: November 29, 2018

Accepted: January 19, 2019

Published: January 22, 2019

Copyright $\odot 2019$ by author(s) and Scientific Research Publishing Inc. This work is licensed under the Creative Commons Attribution International License (CC BY 4.0).

http://creativecommons.org/licenses/by/4.0/ (c) (i) Open Access

\begin{abstract}
The integrated molar absorption coefficients for $v(\mathrm{OH})\left(3655 \mathrm{~cm}^{-1}\right), \delta(\mathrm{OH})$ (Q branch at $1176 \mathrm{~cm}^{-1}$ or whole bands), [ $\left.v\left(\mathrm{CC}_{\text {ring }}\right)+\delta(\mathrm{OH})\right](\mathrm{Q}$ branch at $1344 \mathrm{~cm}^{-1}$ or whole bands) and $\chi(\mathrm{CH})\left(752 \mathrm{~cm}^{-1}\right)$ were determined at $342 \mathrm{~K}$, by recording infrared spectra of pure gaseous phenol at different partial pressure (from 0 to $33 \mathrm{~Pa}$ ). The integrated molar absorption coefficients $(\varepsilon)$ values were obtained with a good reproducibility and the relative uncertainty on the given values is below $2 \%$. The influence of water on the integrated molar absorption coefficients of phenol has been investigated in a large range of $\mathrm{n}_{\text {water }} / \mathrm{n}_{\text {phenol }}$ values (from 0.5 to 6.1 and from 44 to 94 ) using distinct setups. The infrared spectra of a gas mixture containing a constant amount of phenol and different amount of water were recorded (closed cell) whereas in dynamic condition (under flow) the water partial pressure was kept constant at $1.3 \mathrm{kPa}$ and the phenol partial pressure was increased from 0 to $30 \mathrm{~Pa}$. It is here demonstrated that, at 342 or $355 \mathrm{~K}$, the presence of water does not affect the epsilon values of $\delta(\mathrm{OH})$ and $\left[v\left(\mathrm{CC}_{\text {ring }}\right)+\delta(\mathrm{OH})\right]$ bands.
\end{abstract}

\section{Keywords}

Phenol Gas, Integrated Molar Absorption Coefficients Determination, IR Spectroscopy, Phenol-Water Interaction, Phenol Gas Quantification

\section{Introduction}

Due to the recent emergence of bio-fuels, oxygen rich bio-oils are increasingly processed together with fossil resources in classical Fluid Catalytic Cracking unit after a preliminary hydro-deoxygenation step (HDO) has been performed [1] [2]. However, even after such a treatment, bio-fuels still contain oxygenated mo- 
lecules, notably phenolic compounds issued form lignin fragment degradation [1] [3] [4]. Unfortunately, phenol and phenolic compounds are known to be very hazardous for both health (toxic and mutagenic) and environment [5] [6]. It is thus important to control their emission at both the exit of engines powered by $2^{\text {nd }}$ generation bio-fuels and at the outlet of the online catalytic converters. However, before controlling and establishing legal standards for the concentration of emitted phenol and related molecules, it is fundamental to ensure the ability to perform a reliable measurement of the concentration of such compounds in the gas phase. Spectroscopic methods are interesting candidates as they allow both temporal and spatial analysis, a crucial point in the specific case of engine emission and catalytic converter exhaust gases.

Several studies have already been devoted to the spectroscopic analysis of phenol. Assignment of the infrared bands for gaseous, liquid and solid phenol has been elucidated by Evans [7] and completed by Bist et al. [8]. Unfortunately, data related to the integrated molar absorption coefficients $(\varepsilon)$ of the characteristic bands of gaseous phenol are not yet available, which up to now impedes its quantification.

More recently, the interaction between water and phenol has been studied by infrared spectroscopy. Mikami and coworker [9] [10] have shown that for clusters of phenol and water with molar ratio $\mathrm{n}(\mathrm{eau}) / \mathrm{n}(\mathrm{phenol})=1$ to 3 , the $v(\mathrm{OH})$ vibration of phenol shifts to lower wavenumbers with extent ranging from 133 to $312 \mathrm{~cm}^{-1}$ upon increasing water proportion. This phenomenon was attributed to a weakening of the phenol $(\mathrm{O}-\mathrm{H})$ bond during the formation of a hydrogen bond between water and phenol [9]. Similar results have been obtained by Hartland et al. [11]. Indeed, the Raman study of a phenol:water (1:1) cluster has evidenced a shift of $-134 \mathrm{~cm}^{-1}$ of the phenol $v(\mathrm{OH})$ band. Moreover, the authors also reported that the $v(\mathrm{OH})$ vibration is the most affected by the cluster formation. The $v(\mathrm{CO})$ shows a much smaller shift of $+12 \mathrm{~cm}^{-1}$ while the other vibrations modes $\left[v\left(\mathrm{CC}_{\text {ring }}\right), v(\mathrm{CH})\right]$ are only weakly perturbed (from -0.4 to $+3.6 \mathrm{~cm}^{-1}$ ). These results were confirmed by ab-initio and DFT calculations for another phenol:water (1:4) cluster [12]. The former study also predicts an increase of the intensity of the phenol $v(\mathrm{OH})$ band by a factor 38. This appears consistent with results from Watanabe et al. [10] who experimentally showed an increase of the intensity of the $v(\mathrm{OH})$ groups by a factor 5 and 11 for a (1:1) and a (1:3) phenol:water cluster respectively. However, as highlighted by Shimamori et al. [13], the phenol-water clusters in the above cite studies were generated using a supersonic jet expansion. Consequently, the vibrational temperature of the cluster is approximately $100 \mathrm{~K}$ that is far from that encountered in typical conditions used for chemical analysis of interest in the present paper. Furthermore, the authors have shown that an increase of the vibrational temperature from 140 to $175 \mathrm{~K}$ induces a decrease of the shift towards lower wavenumbers $\left(50 \mathrm{~cm}^{-1}\right.$ between the cold and the warm (1:2) phenol:water cluster). Thus, the literature clearly highlights the requirement of evaluating the influence of water content on the phenol integrated molar absorption coefficients in conditions of interest 
for classical chemical analysis (i.e. $\mathrm{T} \geq \mathrm{RT}$ ).

As a consequence, the present study will be first devoted to the measurement of $\varepsilon$ values of representative IR bands [ $\prec(\mathrm{OH}), \delta(\mathrm{OH})$ and $\gamma(\mathrm{CH})]$ for dry gaseous phenol. In a second step, the influence of water vapor on the previously determined values will be investigated by varying the water:phenol molar ratio in a large range. In both case, the measurements will be done in the $340-360 \mathrm{~K}$ range.

\section{Experimental Setup and Methods}

\subsection{Measurement of Integrated Molar Absorption Coefficients}

As shown in Figure 1, the experimental setup was made of a gas cell (optical path $=20.1 \mathrm{~cm})$ equipped with a pressure gauge $(0-10$ Torr $)$. The cell was connected via two ways valves, on one side, to a flask containing pure crystallized phenol in equilibrium with its vapor pressure. On the other side, the cell is connected to a calibrated volume ( $V=2.78 \mathrm{~mL}$ ) being itself connected to an adsorption/vacuum line. As shown in Figure 1, the gas cell was entirely thermo-regulated at $342 \mathrm{~K}$ using Thermocoax ${ }^{\mathrm{TM}}$ heating cable and further insulated with aluminum foil (not shown). The measurement of the temperature was performed via a thermocouple placed between the heating cable and the gas cell.

Prior to the experiment, the setup was evacuated until a residual vacuum of $10^{-6} \mathrm{mbar}$ was reached. Then, increasing phenol vapor pressures (from 0 to $33 \mathrm{~Pa}$ i.e. from 0 to $12 \mu \mathrm{mol} / \mathrm{L}$ at $342 \mathrm{~K}$ ) were introduced in the gas cell and left for stabilization during at least 5 minutes before infrared spectra were recorded. Spectra were recorded on a Nicolet Nexus FT-IR spectrometer, equipped with an MCT detector, by collecting 32 scans at a $0.5 \mathrm{~cm}^{-1}$ resolution. For each stabilized pressure about five spectra of the phenol gas phase were recorded to improve the accuracy of the final results. Finally, the gas cell was evacuated overnight before the experiment was reproduced.

The IR integrated molar absorption coefficients were determined using the Beer-Lambert law for solutions:

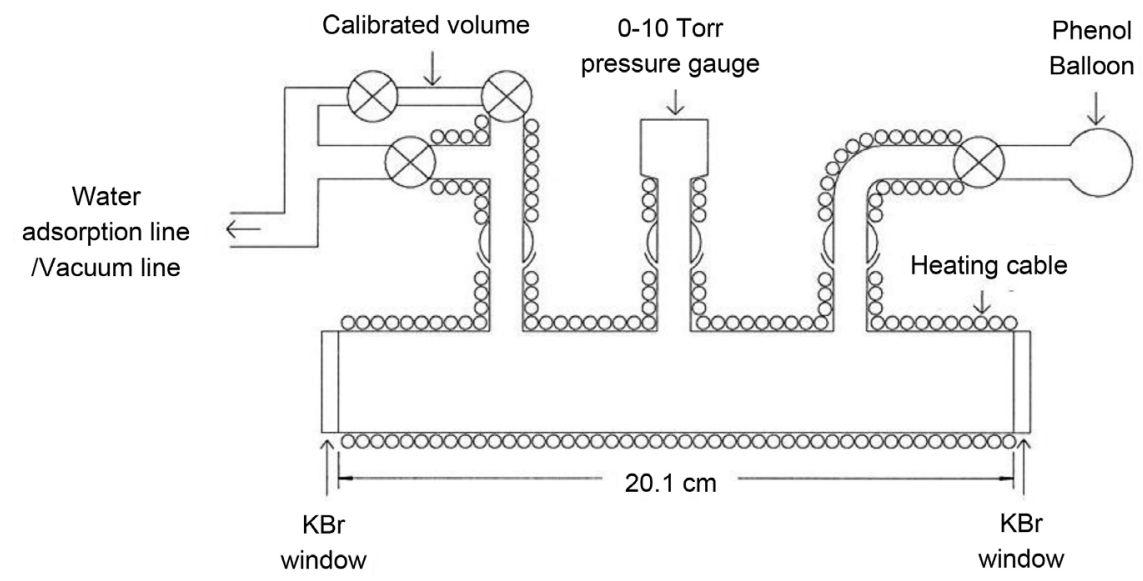

Figure 1. Scheme of the experimental setup used under "static" conditions. 


$$
\mathrm{A}=\int_{v_{1}}^{v_{2}} \mathrm{~A}(v) \cdot d v=\varepsilon l C
$$

where $\mathrm{A}(v), v, \varepsilon, \ell$ and $C$ denote respectively the absorbance, the wavenumber (in $\mathrm{cm}^{-1}$ ), the integrated molar absorption coefficient (in $\mathrm{L} \cdot \mu \mathrm{mol}^{-1} \cdot \mathrm{cm}^{-2}$ ), the optical path (in $\mathrm{cm}$ ) and the phenol concentration (in $\mu \mathrm{mol} \cdot \mathrm{L}^{-1}$ ).

The $\varepsilon$ for the selected bands were calculated directly using the slope of the curves $\mathrm{A}=\mathrm{f}\left(C_{\text {phenol gas }}\right)$ determined by linear regression using the LINEST function of Excel. The uncertainties on the $\varepsilon$ values were estimated from the product between the standard error on the slope (again provided by LINEST) and a confidence factor provided by the Student Law. In the present study, the confidence interval was fixed to $95 \%$.

\subsection{Influence of Water Vapor on the Integrated Molar Absorption Coefficients}

The influence of the water vapor has been studied under both "static" and flow conditions. The experimental procedures followed in each condition are described below.

\subsection{1. "Static" Conditions}

In this case, the setup is the one described at Section 2.1. Prior to the experiment, the setup was evacuated until a residual vacuum of $10^{-6}$ mbar was reached. Then, a phenol vapor pressure of $11.95 \mathrm{~Pa}$ (i.e. $4.20 \mu \mathrm{mol} / \mathrm{L}$ at $342 \mathrm{~K}$ ) was introduced in the gas cell and left for stabilization during at least 20 minutes before recording infrared spectrum. In the next steps, known amounts of water vapor were successively introduced in the gas cell using the calibrated volume. Four introductions of water vapor have been done to reach a $\mathrm{n}\left(\mathrm{H}_{2} \mathrm{O}\right) / \mathrm{n}(\mathrm{PhOH})$ ratio from 1.1 to 6.1. For each condition several spectra (between 7 and 15) were recorded to improve the accuracy of the final result (spectrometer and conditions described in Section 2.1). Finally, the gas cell was evacuated overnight before another experiment was performed. For this last experiment, the initial phenol vapor pressure was increased to $27.07 \mathrm{~Pa}$ (i.e. $8.47 \mu \mathrm{mol} / \mathrm{L}$ at $342 \mathrm{~K}$ ) and the $\mathrm{n}\left(\mathrm{H}_{2} \mathrm{O}\right) / \mathrm{n}(\mathrm{PhOH})$ ratio was varied from 0.6 to 3.4 .

\subsubsection{Dynamic (Flow) Conditions}

As shown in Figure 2, the experimental setup was made of a gas cell (optical path $=24.4 \mathrm{~cm}$ ) connected to a system allowing the preparation of gas mixtures based on Argon (carrier and dilution gas), water and phenol. The phenol partial pressure was varied from 0 to $30 \mathrm{~Pa}$ (i.e. 0 to $11.3 \mu \mathrm{mo} / \mathrm{L}$ at $355 \mathrm{~K}$ ) by changing the temperature of the saturator from 306 to $313 \mathrm{~K}$ and the water partial pressure was fixed to $1.3 \mathrm{kPa}$ by using a CEM-system provided by Bronkhorst ${ }^{\circledR}$. All the setup was thermo-regulated at $355 \mathrm{~K}$ using Thermocoax ${ }^{\mathrm{TM}}$ heating cable and further insulated with aluminum foil to avoid phenol and water condensation. As for static conditions, the measurement of the temperature was performed via a thermocouple placed between the heating cable and the gas cell. 


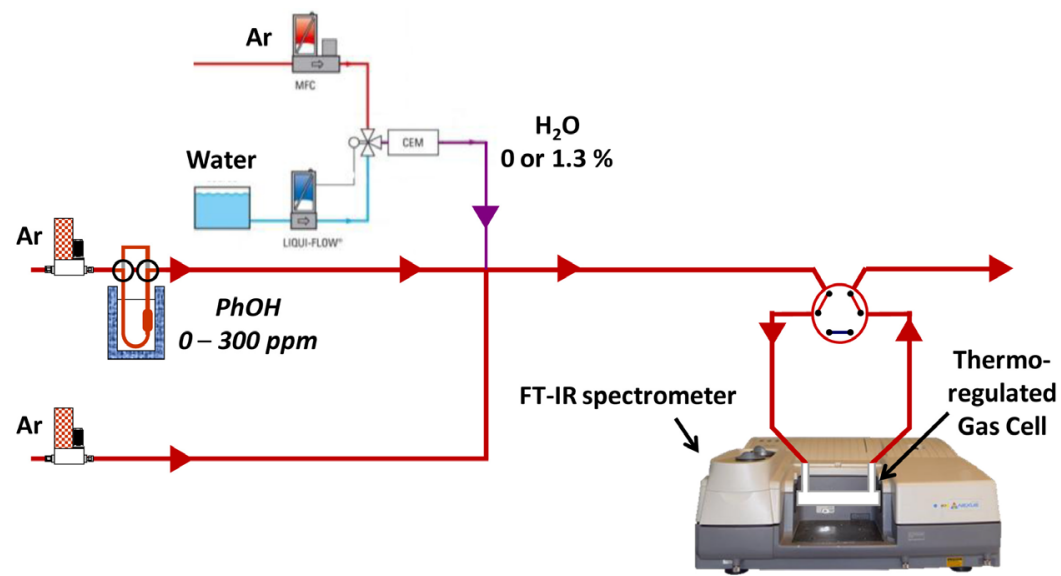

Figure 2. Scheme of the experimental setup used for measurement under dynamic conditions.

More precisely, for each of the four phenol partial pressures, more than 20 spectrum of the gas phase have been recorded without water vapor and then in presence of water. In these conditions, the $\mathrm{n}\left(\mathrm{H}_{2} \mathrm{O}\right) / \mathrm{n}(\mathrm{PhOH})$ ratio was varied from 44 to 94 .

Spectra were recorded on a Nicolet iS50 FT-IR spectrometer, equipped with an MCT detector, by collecting 64 scans at a $0.5 \mathrm{~cm}^{-1}$ spectral resolution.

\subsubsection{Methodology}

Since complementary experiments were performed with cells presenting distinct optical paths and taking into account that the $\mathrm{n}\left(\mathrm{H}_{2} \mathrm{O}\right) / \mathrm{n}(\mathrm{PhOH})$ ratio varied in a broad range ( 0.6 to 94 ) using these distinct cells, it was decided to investigate the ratio between two bands (one involving $\mathrm{OH}$ vibration modes and one assigned to $\mathrm{CH}$ vibration modes [7] [8]). This "normalization" allows a more precise determination of the impact or not of the water content. Then, in the following, several ratios have been calculated:

In static conditions.

$$
\frac{\mathrm{A}(\delta(\mathrm{OH}))}{\mathrm{A}(\gamma(\mathrm{CH}))}=\frac{\mathrm{A}\left(1176 \mathrm{~cm}^{-1}\right)}{\mathrm{A}\left(752 \mathrm{~cm}^{-1}\right)} \text { and } \frac{\mathrm{A}\left(v\left(\mathrm{CC}_{\text {ring }}\right)+\delta(\mathrm{OH})\right)}{\mathrm{A}(\gamma(\mathrm{CH}))}=\frac{\mathrm{A}\left(1344 \mathrm{~cm}^{-1}\right)}{\mathrm{A}\left(752 \mathrm{~cm}^{-1}\right)}
$$

\section{In dynamic conditions.}

$$
\frac{\mathrm{A}(\delta(\mathrm{OH}))}{\mathrm{A}(\gamma(\mathrm{CH}))}=\frac{\mathrm{A}\left(1176 \mathrm{~cm}^{-1}\right)}{\mathrm{A}\left(881 \mathrm{~cm}^{-1}\right)} \text { and } \frac{\mathrm{A}\left(v\left(\mathrm{CC}_{\text {ring }}\right)+\delta(\mathrm{OH})\right)}{\mathrm{A}(\gamma(\mathrm{CH}))}=\frac{\mathrm{A}\left(1344 \mathrm{~cm}^{-1}\right)}{\mathrm{A}\left(881 \mathrm{~cm}^{-1}\right)}
$$

The detector whose windows only allowed analysis above $800 \mathrm{~cm}^{-1}$ imposed the choice of the band at $881 \mathrm{~cm}^{-1}$ even though less intense than the one at 752 $\mathrm{cm}^{-1}$.

\subsection{Bands Integration}

Table 1 lists the vibration modes of interest in the present study and indicates the integration range (similar base line limits) for each band or group of bands. 
Table 1. Integration and baseline limits of different selected vibration modes [7] [8].

\begin{tabular}{cccccccc}
\hline $\begin{array}{c}\text { Vibration } \\
\text { modes }\end{array}$ & $v(\mathrm{OH})$ & $\begin{array}{c}\gamma\left(\mathrm{CC}_{\text {ring }}\right) \\
+\delta(\mathrm{OH}) \\
\mathrm{Q} \text { branch }\end{array}$ & $\begin{array}{c}\gamma\left(\mathrm{CC}_{\text {ring }}\right) \\
+\delta(\mathrm{OH}) \\
\text { whole bands }\end{array}$ & $\begin{array}{c}\delta(\mathrm{OH}) \\
\mathrm{Q} \text { branch }\end{array}$ & $\begin{array}{c}\delta(\mathrm{OH}) \\
\text { whole bands }\end{array}$ & $\gamma(\mathrm{CH})$ & $\gamma(\mathrm{CH})$ \\
\hline $\begin{array}{c}\text { Bands positions } \\
\left(\mathrm{cm}^{-1}\right)\end{array}$ & 3655 & 1344 & $\begin{array}{c}1355+1344+ \\
1335\end{array}$ & 1176 & $\begin{array}{c}1184+1176+ \\
1168\end{array}$ & 752 & 881 \\
$\begin{array}{c}\text { Integration and } \\
\text { baseline limits } \\
\left(\mathrm{cm}^{-1}\right)\end{array}$ & -5657.2 & 1345.2 & 1365.0 & 1177.8 & 1194.0 & 752.6 & 882.6 \\
\hline
\end{tabular}

\section{Results and Discussion}

\subsection{Pure Gaseous Phenol}

Figure 3 presents the evolution of the infrared spectra of pure gaseous phenol as a function of the phenol concentration. The $v(\mathrm{OH}),\left[v\left(\mathrm{CC}_{\text {ring }}\right)+\delta(\mathrm{OH})\right]$ and $\delta(\mathrm{OH})$ (Figure 3(a)-3(c)) are vibration-rotation modes whose symmetry is at the origin of the specific shape of these vibrations i.e. a central sharp peak $(\mathrm{Q}$ branch) and two lateral bands ( $\mathrm{P}$ and $\mathrm{Q}$ branch). According to the spectra, $v(\mathrm{OH})$ bands are at 3661,3655 and $3648 \mathrm{~cm}^{-1},\left[\gamma\left(\mathrm{CC}_{\text {ring }}\right)+\delta(\mathrm{OH})\right]$ bands at 1350,1344 and $1335 \mathrm{~cm}^{-1}$ and $\delta(\mathrm{OH})$ bands at 1184,1176 and $1168 \mathrm{~cm}^{-1}$. All these values are in good agreement with Evans results [7]. The $\gamma(\mathrm{CH})$ vibration mode (Figure 3(d)) gives a sharp band at $752 \mathrm{~cm}^{-1}$ as also previously reported [7] [8].

As evidenced by Figure 3, whatever the vibration modes $v(\mathrm{OH}),\left[v\left(\mathrm{CC}_{\text {ring }}\right)+\right.$ $\delta(\mathrm{OH})], \delta(\mathrm{OH})$ or $\gamma(\mathrm{CH})$, the positions of the bands are not affected by an increase of the phenol concentration. In addition, the development of extra bands was not detected. This suggests that phenol molecules are isolated (i.e. without interaction with other phenol molecules) and could be considered as monomers.
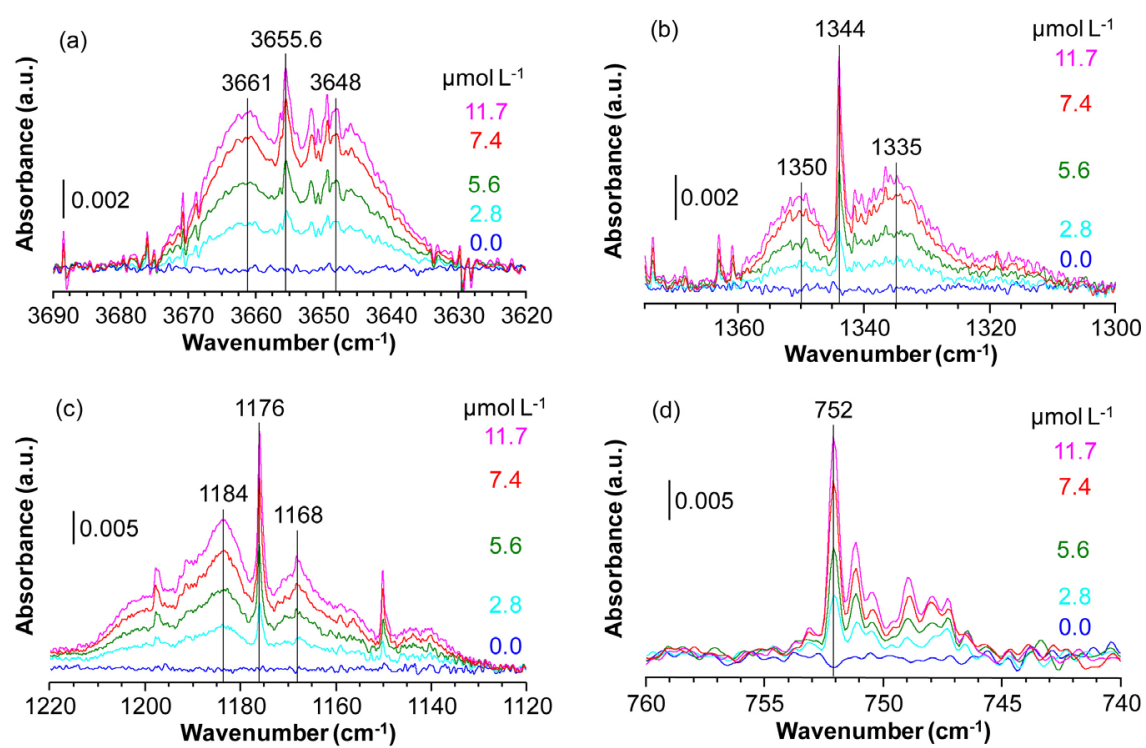

Figure 3. Evolution of: (a) $v(\mathrm{OH})$; (b) $v\left(\mathrm{CC}_{\text {ring }}\right)+\delta(\mathrm{OH})$; (c) $\delta(\mathrm{OH})$ and $(\mathrm{d}) \gamma(\mathrm{CH})$ bands as a function of the phenol concentration $\left(0.0 ; 2.8 ; 5.6 ; 7.4\right.$ and $\left.11.7 \mu \mathrm{mol} \cdot \mathrm{L}^{-1}\right)$. Spectra recorded under static conditions. 
Indeed, according to previous works [11] [14], the formation of dimers or trimers would induce a large shift of the $v(\mathrm{OH})$ band to lower wavenumbers. In addition, based on the results from Książczak et al. [15], it was calculated that at $342 \mathrm{~K}$ and with the highest phenol pressure (i.e. $33 \mathrm{~Pa}$ ), no more than $3 \%$ of the phenol molecules are implied in the formation of dimers. Thus, in the following, the formation of phenol oligomers will be neglected.

Figure 4 represents the evolution of the area of the selected IR bands as a function of the phenol concentration. The results clearly show a linear evolution of the area as a function of the phenol concentration. Furthermore, data points arising from two different experiments (full vs open similar symbol) present a close evolution that underlines the good reproducibility of the results. This is confirmed by the $\varepsilon$ values calculated for both experiments (Table 2) whose confidence interval recovers for each band or group of bands. Taking into account the reproducibility of the results and aiming at improving the accuracy of the $\varepsilon$ values, it was decided to recalculate it from the whole experimental points. Results are presented in the third column of Table 2.

As evidenced by Figure 4(a) and Figure 4(b) and Table 2, the integration of the whole band for both the $\left[v\left(\mathrm{CC}_{\text {ring }}\right)+\delta(\mathrm{OH})\right]$ and the $\delta(\mathrm{OH})$ one, rather than the $\mathrm{Q}$ branch only, increases the sensitivity by a factor 10 and 7 respectively. This
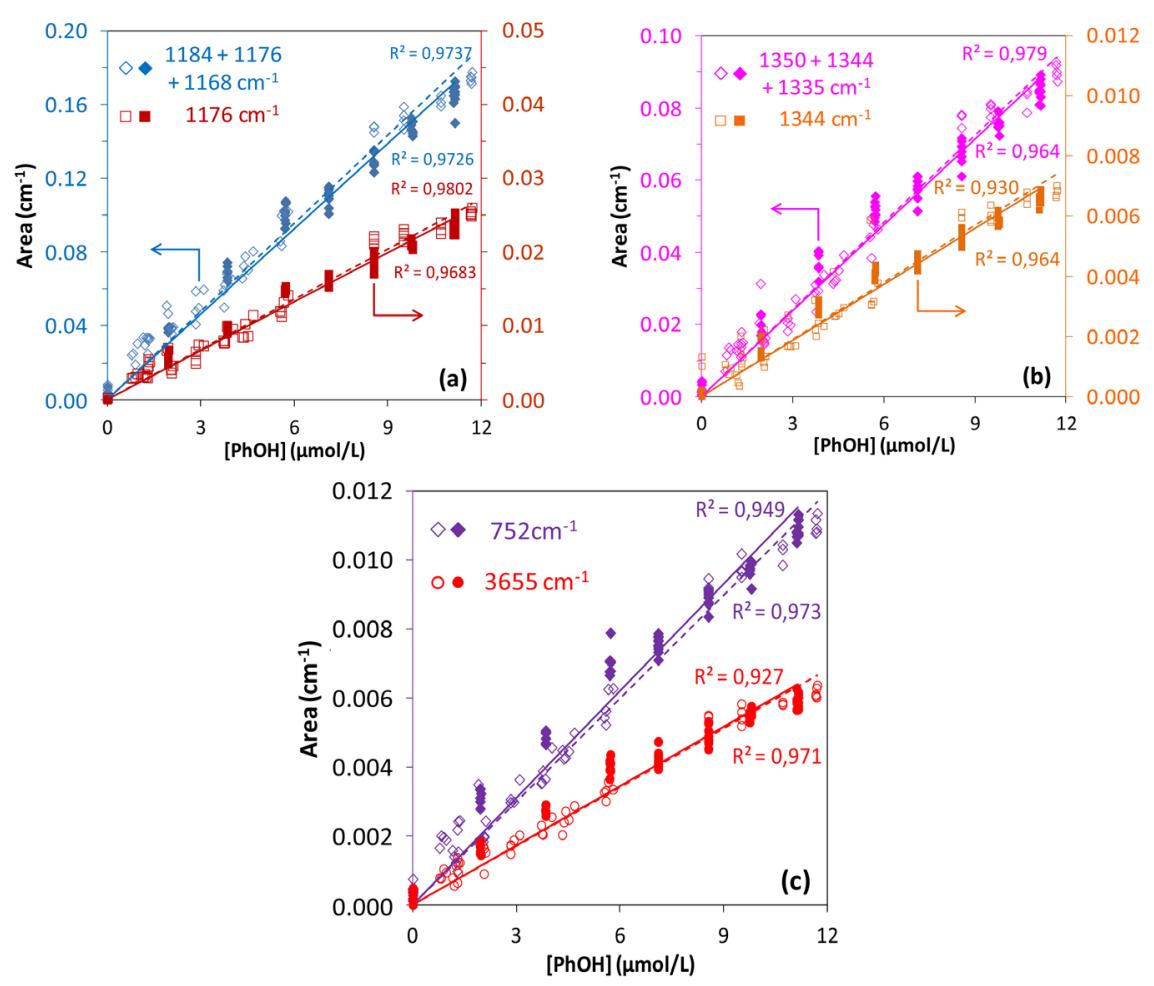

Figure 4. Evolution of the area of: (a) $\delta(\mathrm{OH})$ at $1184 ; 1176$ and $1168 \mathrm{~cm}^{-1}$ (diamond symbol) and $\delta(\mathrm{OH})$ at $1176 \mathrm{~cm}^{-1}$ (square symbol); (b) $v\left(\mathrm{CC}_{\text {ring }}\right)+\delta(\mathrm{OH})$ at $1350 ; 1344$ and $1335 \mathrm{~cm}^{-1}$ (diamond symbol) and $\gamma\left(\mathrm{CC}_{\text {ring }}\right)+\delta(\mathrm{OH})$ at $1344 \mathrm{~cm}^{-1}$ (square symbol) (c) $\gamma(\mathrm{CH})$ at $752 \mathrm{~cm}^{-1}$ (diamond symbol) and $\gamma(\mathrm{OH})$ at $3655 \mathrm{~cm}^{-1}$ (circle symbol) as a function of the phenol concentration. Open and full symbols correspond to the $1^{\text {st }}$ and $2^{\text {nd }}$ experiment respectively. 
Table 2. Integrated molar absorption coefficients $(\varepsilon)$ values of selected bands in $\mathrm{L} \cdot \mu \mathrm{mol}^{-1}$ $\mathrm{cm}^{-2}$ calculated from spectra recorded under static conditions.

\begin{tabular}{cccc}
\hline Bands positions $\left(\mathrm{cm}^{-1}\right)$ & $1^{\text {st }}$ experiment & $2^{\text {nd }}$ experiment & Experiment 1 and 2 \\
\hline 3655 & $(2.828+/-0.065) \cdot 10^{-5}$ & $(2.854+/-0.063) \cdot 10^{-5}$ & $(2.845+/-0.045) \cdot 10^{-5}$ \\
1344 & $(3.064+/-0.061) \cdot 10^{-5}$ & $(3.093+/-0.051) \cdot 10^{-5}$ & $(3.083+/-0.038) \cdot 10^{-5}$ \\
$1350+1344+1335$ & $(3.999+/-0.080) \cdot 10^{-4}$ & $(3.945+/-0.064) \cdot 10^{-4}$ & $(3.964+/-0.049) \cdot 10^{-4}$ \\
1176 & $(1.124+/-0.022) \cdot 10^{-4}$ & $(1.100+/-0.017) \cdot 10^{-4}$ & $(1.109+/-0.013) \cdot 10^{-4}$ \\
$1184+1176+1168$ & $(7.90+/-0.17) \cdot 10^{-4}$ & $(7.66+/-0.11) \cdot 10^{-4}$ & $(7.742+/-0.095) \cdot 10^{-4}$ \\
752 & $(4.97+/-0.11) \cdot 10^{-5}$ & $(5.138+/-0.096) \cdot 10^{-5}$ & $(5.079+/-0.072) \cdot 10^{-5}$ \\
\hline
\end{tabular}

could be very helpful to improve the accuracy of chemical analysis, however the choice of the right $\varepsilon$ value and its associated integration range will for sure depends on the application. Indeed, the integration of a large spectral window increases the probability of overlapping with bands arising from other molecules. As an example, the phenol band at 1350 and $1335 \mathrm{~cm}^{-1}$ superimpose with bands from water.

\subsection{Influence of Water Vapor on the Integrated Molar Absorption Coefficients Values of Phenol}

\subsubsection{Analysis under Static Conditions}

In this study, stable pressure of phenol was introduced into the gas cell via the phenol flask (11.8 or $24.1 \mathrm{~Pa}$ ) and increasing water partial pressure was then introduced into the cell via the calibrated volume (see Figure 1). As shown on Figure $5(\mathrm{a})$ and Figure $5(\mathrm{~b})$, the $\delta(\mathrm{OH})$ and $\left[{ }\left(\mathrm{CC}_{\text {ring }}\right)+\delta(\mathrm{OH})\right]$ vibration modes at 1176 and $1344 \mathrm{~cm}^{-1}$ are not affected by the introduction of water. Indeed, the bands position remains constant at $\pm 0.01 \mathrm{~cm}^{-1}$ while Figure 5 (b) clearly shows the development of the bands of gaseous water. Figure 5(c) also indicates an absence of influence of water on the $v(\mathrm{OH})$ vibration band position that remains constant at $3655.8 \mathrm{~cm}^{-1}$ even if the strong band from water at $3656.1 \mathrm{~cm}^{-1}$ limits the accuracy of the measurement. In addition, no extra band associated to water-phenol cluster was observed. These results suggest that, under our experimental conditions, interactions between water and phenol are not strong enough to induce noticeable perturbation of the observed vibration modes. Indeed, according to the literature, the strong shift of the $v(\mathrm{OH})$ band [9] [11] [12] and the smaller one of the $\delta(\mathrm{OH})$ and the $\left[v\left(\mathrm{CC}_{\text {ring }}\right)+\delta(\mathrm{OH})\right]$ bands [12] is related to the formation of $\mathrm{H}$-bonds between phenol and water that weaken the phenol intrinsic $(\mathrm{O}-\mathrm{H})$ bond.

The evaluation of the influence of the water vapor pressure on the integrated molar absorption coefficients has been done by following the evolution of the ratio between the area of a given band, possibly affected by the presence of water and the one of a $\mathrm{CH}$ band, known to be unaffected by water [11] [12] as a function of the water partial pressure (for more detail see experimental part). This methodology was applied in order to get rid of the phenol concentration decrease 

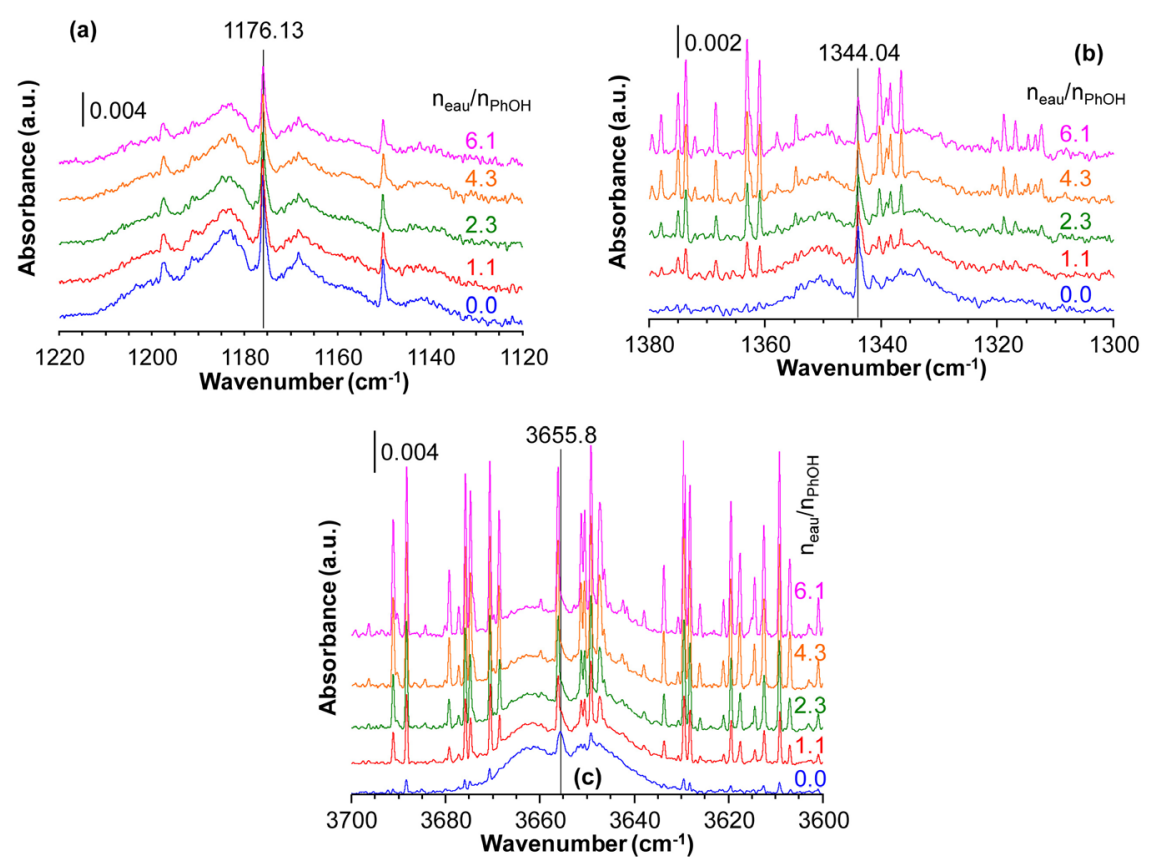

Figure 5. Spectra recorded for different water-phenol mixtures with [Phenol] $\sim 4.2$ $\mu \mathrm{mol} \cdot \mathrm{L}^{-1}$. (a) $\delta(\mathrm{OH})$; (b) $v\left(\mathrm{CC}_{\text {ring }}\right)+\delta(\mathrm{OH})$ and (c) $v(\mathrm{OH})$ region. From bottom to top: $\mathrm{n}_{\text {eau }} / \mathrm{n}_{\text {phenol }}=0$ (pure phenol); $1.1 ; 2.3 ; 4.3$ and 6.1.

effect that takes place during the successive introduction of water vapor. Indeed, the area of the whole phenol bands slightly decreases after each water introduction (see Figure 5), which prevents from a direct conclusion regarding the influence of water on the $\varepsilon$ values.

Figure 6(a) and Figure 6(b) present the evolution of the $\mathrm{A}\left(1176 \mathrm{~cm}^{-1}\right) / \mathrm{A}(752$ $\left.\mathrm{cm}^{-1}\right)$ ratio and the $\mathrm{A}\left(1344 \mathrm{~cm}^{-1}\right) / \mathrm{A}\left(752 \mathrm{~cm}^{-1}\right)$ ratio as a function of the water partial pressure for two different phenol partial pressure (i.e. 12 and $24 \mathrm{~Pa}$ respectively). For information, the first conditions corresponds to $[\mathrm{PhOH}]=4.2 \mu \mathrm{mol} \cdot \mathrm{L}^{-1}$ and the second one to $[\mathrm{PhOH}]=8.5 \mu \mathrm{mol} \cdot \mathrm{L}^{-1}$. For each water pressure the calculated ratio presents some non-negligible variations that are attributed to erratic variations of the area of chosen bands and not to any instability of the system. Indeed, Figure $6(\mathrm{c})$ shows the evolution of the $\mathrm{A}\left(1176 \mathrm{~cm}^{-1}\right) / \mathrm{A}\left(752 \mathrm{~cm}^{-1}\right)$ ratio with time (from 13 to 19 measurements under similar conditions) for which spectra were recorded under three different water partial pressure (i.e. 0; 27 and $70 \mathrm{~Pa}$ ) and a phenol partial pressure "fixed" at $12 \mathrm{~Pa}$. It appears clear, from this figure that the $\mathrm{A}\left(1176 \mathrm{~cm}^{-1}\right) / \mathrm{A}\left(752 \mathrm{~cm}^{-1}\right)$ ratio does not follow a monotonous evolution and provides evidence for an erratic distribution of experimental data due to repeatability uncertainty. This conclusion is in agreement with a lower distribution of experimental points when increasing the phenol pressure (Figure 6(a) to Figure 6(b)). Indeed, the higher area of IR bands resulting from a higher phenol partial pressure induces an improvement of the signal to noise ratio and thus a decrease of the reproducibly uncertainty.

As a consequence, Figure 6(a) and Figure 6(b) also show that the calculated ratios are unaffected by increasing the water partial pressure. This result may 

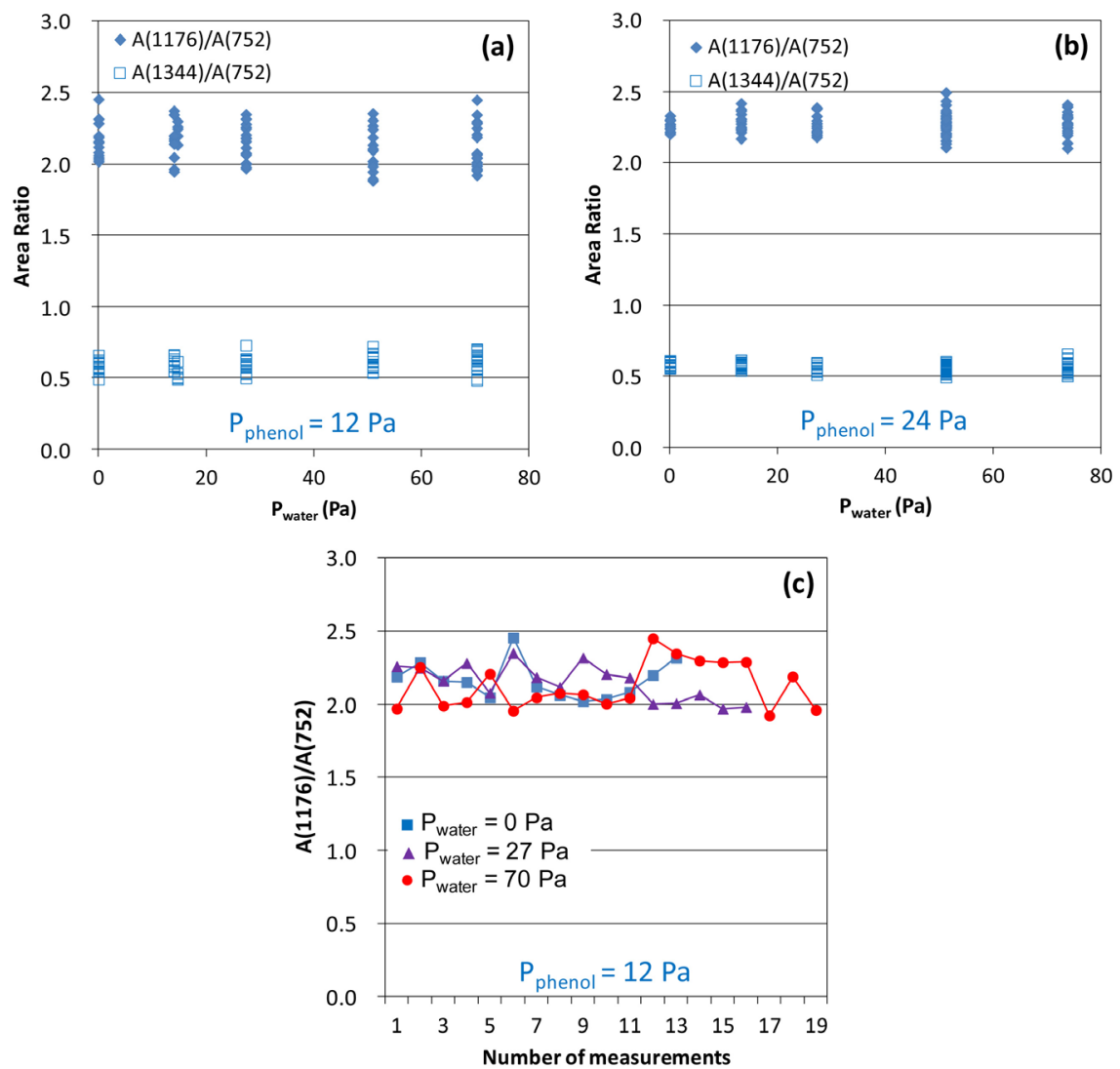

Figure 6. Evolution of the ratio $\mathrm{A}\left(1176 \mathrm{~cm}^{-1}\right) / \mathrm{A}\left(752 \mathrm{~cm}^{-1}\right)$ and $\mathrm{A}\left(1344 \mathrm{~cm}^{-1}\right) / \mathrm{A}(752$ $\mathrm{cm}^{-1}$ ) as a function of the water partial pressure for a phenol partial pressure of (a) $12 \mathrm{~Pa}$ and (b) $24 \mathrm{~Pa}$; (c) Variation of the ratio $\mathrm{A}\left(1176 \mathrm{~cm}^{-1}\right) / \mathrm{A}\left(752 \mathrm{~cm}^{-1}\right)$ as a function of time (number of spectrum recorded under similar condition) with $\mathrm{P}_{\text {phenol }}=12 \mathrm{~Pa} ; \mathrm{P}_{\text {water }}=0 ; 27$ and $70 \mathrm{~Pa}$.

have two rather distinct explanations. Either none of the integrated molar absorption coefficient of bands at 1176, 1344 and $752 \mathrm{~cm}^{-1}$ are affected by the presence of water or on the contrary the whole integrated molar absorption coefficients are modified but by exactly the same factor. The later explanation is however highly unlikely notably as it is known from theoretical calculations that water molecules do not interact with $\mathrm{CH}$ group of phenol [10] [12] [13] [16]. Thus, modification of the dipolar moment of the $\mathrm{CH}$ groups should be only due to inductive effect coming from the interaction between phenol $(\mathrm{OH})$ group and water via $\mathrm{H}$-bonding that should have almost no influence on the $\mathcal{\varepsilon}$ values of the $\mathrm{CH}$ groups. It can be then concluded that the $\varepsilon$ values of the $\delta(\mathrm{OH})$ and $\left[v\left(\mathrm{CC}_{\text {ring }}\right)+\delta(\mathrm{OH})\right]$ bands at 1176 and $1344 \mathrm{~cm}^{-1}$ are not affected by the presence of water. This conclusion is in agreement with the analysis of the infrared spectra (no shift and no extra bands) that revealed very weak interaction between phenol and water in the present conditions.

The water and phenol pressures were chosen so that the $n_{\text {water }} / n_{\text {phenol }}$ ratio lies between 1.1 and 6.1 (Figure 6(a)) and 0.6 and 3.4 (Figure 6(b)) that mostly corresponds to ratios already studied in the literature [9] [11] [12]. These pre- 
vious studies evidenced [9] [11] or predicted [12] not only a shift of the $v(\mathrm{OH})$ band upon increasing the water/phenol ratio from 1 to 4 but also an increase of this $v(\mathrm{OH})$ band intensity [10] [12]. Nevertheless, none of these phenomena was observed in the present study. Quite distinct measurement temperatures tentatively explain these apparent discrepancies. Indeed, the water-phenol clusters reported in previous works were generated by supersonic jet expansion. Consequently, the vibrational temperature of the cluster is approximately $100 \mathrm{~K}$ [13] that is far from $342 \mathrm{~K}$ used in the present study. At low temperature, the interaction of water with phenol is highly favored and would explain why it is detected at $\sim 100 \mathrm{~K}$ and not at $342 \mathrm{~K}$. This is supported by a conclusion from Shimamori et al. [13] who showed that a small increase of temperature from 140 to $175 \mathrm{~K}$ induces a strong modification of the H-bonded structure of a (1:2) phenol:water cluster leading to a strong decrease of the $v(\mathrm{OH})$ band shift. It is thus proposed that in our present study, the more than $200 \mathrm{~K}$ higher temperature would not induce any variation of the position and of the $\varepsilon$ values of the considered bands.

\subsubsection{Analysis under Dynamic Conditions}

In the previous section, the influence of water was considered at a temperature representative for classical analytic conditions $(\mathrm{T} \geq \mathrm{RT})$ and phenol partial pressures ( $\mathrm{P}_{\text {phenol }}$ up to $24 \mathrm{~Pa}$ whereas the equilibrium vapor pressure is $37 \mathrm{~Pa}$ at $293 \mathrm{~K}$ [17]) enabling the quantification of phenol traces in the gas phase. However, the used water pressure $(\leq 75 \mathrm{~Pa})$ is far from representative of either ambient air or combustion exhaust gases. Indeed, at $293 \mathrm{~K}$, the water equilibrium vapor pressure is $2.3 \mathrm{kPa}$ [17] and in some specific case the water partial pressure can reach 10 to $12 \mathrm{kPa}$ notably at engine exhaust [18]. It was then important to confirm the previous conclusion when higher water partial pressure is present.

In this part, it was decided to increase phenol partial pressure (from 14 to $30 \mathrm{~Pa}$ ) and to collect infrared spectra at each pressure with or without water $\left(\mathrm{P}_{\text {water }}=0\right.$ or $1.3 \mathrm{kPa}$ ). For more detail see experimental part (Section 2.2.2). Figure 7(a) thus presents the evolution of the $\mathrm{A}\left(1176 \mathrm{~cm}^{-1}\right) / \mathrm{A}\left(881 \mathrm{~cm}^{-1}\right)$ ratio and $\mathrm{A}(1344$ $\left.\mathrm{cm}^{-1}\right) / \mathrm{A}\left(881 \mathrm{~cm}^{-1}\right)$ ratio as a function of the phenol partial pressure with or without water partial pressure. First, it is worth noting that under such a water pressure, it was necessary to correct the area of the $\left[v\left(\mathrm{CC}_{\text {ring }}\right)+\delta(\mathrm{OH})\right]$ band at $1344 \mathrm{~cm}^{-1}$ from contribution of a small band at $1344 \mathrm{~cm}^{-1}$ arising from gaseous water. As observed in the previous section, the calculated ratios present variations in a larger extent. This variations have again been attributed to erratic variation of the measured area and notably those of the $\gamma(\mathrm{CH})$ band at $881 \mathrm{~cm}^{-1}$. Indeed, this band is approximately 10 times smaller than that at $752 \mathrm{~cm}^{-1}$. The signal to noise ratio is then lower and induces a larger variation of the calculated ratios. In addition, Figure 7 (b) clearly shows the stability of the system since the ratios can be considered constant taking into account the random fluctuation.

Furthermore, according to Figure 7(a) the calculated ratios do not depend on the presence of water and whatever the phenol partial pressure. These last results 

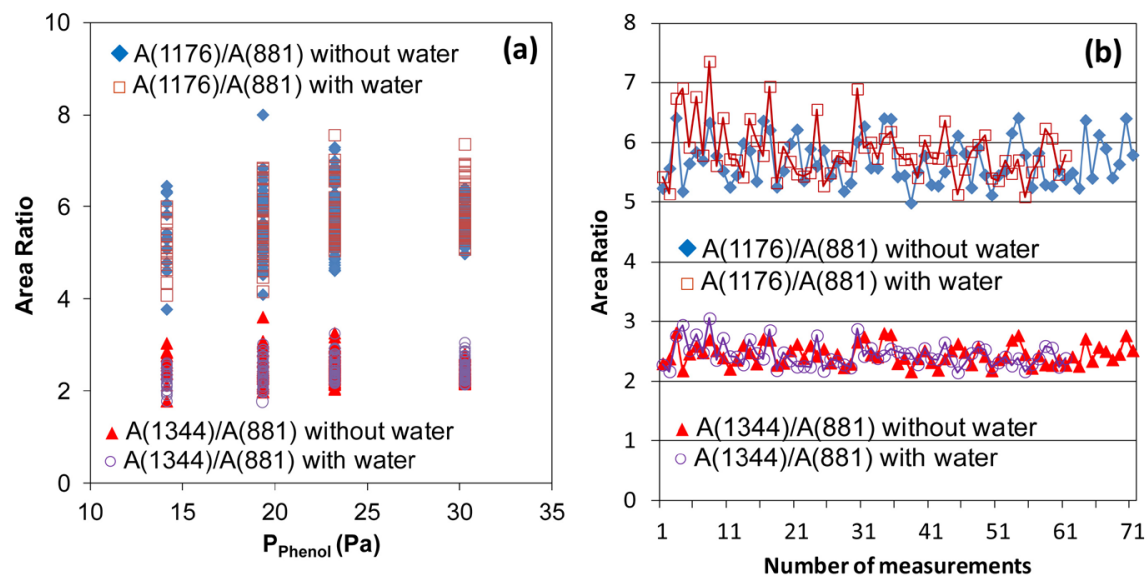

Figure 7. Evolution of the (a) $\mathrm{A}\left(1176 \mathrm{~cm}^{-1}\right) / \mathrm{A}\left(881 \mathrm{~cm}^{-1}\right)$ ratio and $\mathrm{A}\left(1344 \mathrm{~cm}^{-1}\right) / \mathrm{A}(881$ $\mathrm{cm}^{-1}$ ) ratio as a function of the phenol partial pressure with or without water partial pressure $\left(\mathrm{P}_{\text {water }}=0\right.$ or $\left.1.3 \mathrm{kPa}\right)$; (b) Variation of the ratio $\mathrm{A}\left(1176 \mathrm{~cm}^{-1}\right) / \mathrm{A}\left(881 \mathrm{~cm}^{-1}\right)$ and $\mathrm{A}\left(1344 \mathrm{~cm}^{-1}\right) / \mathrm{A}\left(881 \mathrm{~cm}^{-1}\right)$ as a function of time (number of spectrum recorded under similar condition) with $\mathrm{P}_{\text {phenol }}=30 \mathrm{~Pa} ; \mathrm{P}_{\text {water }}=0$ or $1.3 \mathrm{kPa}$.
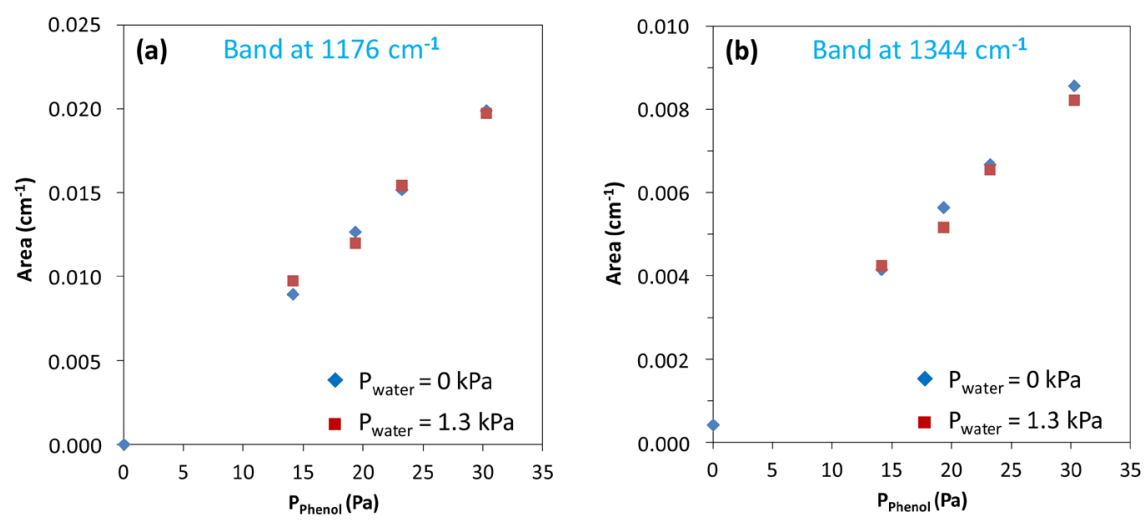

Figure 8. Evolution of the area of (a) $\delta(\mathrm{OH})$ at $1176 \mathrm{~cm}^{-1}$ and (b) $\left[\gamma\left(\mathrm{CC}_{\text {ring }}\right)+\delta(\mathrm{OH})\right]$ at $1344 \mathrm{~cm}^{-1}$ as a function of the phenol partial pressure with or without water

confirm that, under our experimental conditions, the integrated molar absorption coefficients of the investigated IR bands are not influenced by the presence of a large excess of water. Indeed, under our dynamic conditions, the $\mathrm{n}_{\text {water }} / \mathrm{n}_{\text {phenol }}$ ratio was varied from 44 and 94 . This important conclusion is further confirmed by Figure 8 that shows the evolution of the average area of phenol bands at 1176 and $1344 \mathrm{~cm}^{-1}$ as a function of the phenol partial pressure with or without water. It clearly provides evidence that, whatever the phenol pressure, the bands area values do not change in presence of $1.3 \mathrm{kPa}$ of water.

\section{Conclusions}

The integrated molar absorption coefficients for $v(\mathrm{OH})\left(3655 \mathrm{~cm}^{-1}\right), \delta(\mathrm{OH})(\mathrm{Q}$ branch at $1176 \mathrm{~cm}^{-1}$ or whole bands), $\left[\left(\mathrm{CC}_{\text {ring }}\right)+\delta(\mathrm{OH})\right]\left(\mathrm{Q}\right.$ branch at $1344 \mathrm{~cm}^{-1}$ or whole bands) and $\gamma(\mathrm{CH})\left(752 \mathrm{~cm}^{-1}\right)$ were determined from infrared spectra of pure gaseous phenol. The $\varepsilon$ values were obtained with a good reproducibility and 
the relative uncertainty on the given values is below $2 \%$.

The influence of water on the integrated molar absorption coefficients of phenol has been investigated in a large range of $\mathrm{n}_{\text {water }} / \mathrm{n}_{\text {phenol }}$ values using distinct setups (from 0.5 to 6.1 and from 44 to 94). It was demonstrated that, at 342 or $355 \mathrm{~K}$, the presence of water does not affect the epsilon values of $\delta(\mathrm{OH})$ and $\left[\imath\left(\mathrm{CC}_{\text {ring }}\right)+\delta(\mathrm{OH})\right]$ bands.

\section{Acknowledgements}

The authors acknowledge the financial support of the French Agence Nationale de la Recherche (ANR), through the program Investissements d'Avenir (ANR-10-LABX-09-01), LabEX EMC3 and European Union in the framework of the European Regional Development Fund (FEDER)

\section{Conflicts of Interest}

The authors declare no conflicts of interest regarding the publication of this paper.

\section{References}

[1] Fogassy, G., Thegarid, N., Schuurman, Y. and Mirodatos, C. (2011) From Biomass to Bio-Gasoline by FCC Co-Processing: Effect of Feed Composition and Catalyst Structure on Product Quality. Energy \& Environmental Science, 4, 5068-5076. https://doi.org/10.1039/c1ee02012a

[2] de Miguel Mercader, F., Groeneveld, M.J., Kersten, S.R.A., Way, N.W.J., Schaverien, C.J. and Hogendoorn, J.A. (2010) Production of Advanced Biofuels: Co-Processing of Upgraded Pyrolysis Oil in Standard Refinery Units. Applied Catalysis B: Environmental, 96, 57-66. https://doi.org/10.1016/j.apcatb.2010.01.033

[3] Graça, I., Fernandes, A., Lopes, J.M., Ribeiro, M.F., Laforge, S., Magnoux, P. and Ramôa Ribeiro, F. (2011) Bio-Oils and FCC Feedstocks Co-Processing: Impact of Phenolic Molecules on FCC Hydrocarbons Transformation over MFI. Fuel, 90, 467-476. https://doi.org/10.1016/j.fuel.2010.09.028

[4] Bertero, M. and Sedran, U. (2013) Upgrading of Bio-Oils over Equilibrium FCC Catalysts. Contribution from Alcohols, Phenols and Aromatic Ethers. Catalysis Today, 212, 10-15. https://doi.org/10.1016/j.cattod.2013.03.016

[5] Vermerris, W. and Nicholson, R. (2006) Phenolic Compounds and Their Effects on Human Health. In: Phenolic Compound Biochemistry, Springer, Dordrecht, 235-255. https://doi.org/10.1007/978-1-4020-5164-7_7

[6] Calace, N., Nardi, E., Petronio, B. and Pietroletti, M. (2002) Adsorption of Phenols by Papermill Sludges. Environmental Pollution, 118, 315-319. https://doi.org/10.1016/S0269-7491(01)00303-7

[7] Evans, J.C. (1960) The Vibrational Spectra of Phenol and Phenol-OD. Spectrochimica Acta, 16, 1382-1392. https://doi.org/10.1016/S0371-1951(60)80011-2

[8] Bist, H.D., Brand, J.C.D. and Williams, D.R. (1967) The Vibrational Spectrum and Torsion of Phenol. Journal of Molecular Spectroscopy, 24, 402-412. https://doi.org/10.1016/0022-2852(67)90104-X

[9] Tanabe, S., Ebata, T., Fujii, M. and Mikami, N. (1993) OH Stretching Vibrations of Phenol- $\left(\mathrm{H}_{2} \mathrm{O}\right)_{n}(n=1-3)$ Complexes Observed by IR-UV Double-Resonance Spec- 
troscopy. Chemical Physics Letters, 215, 347-352.

https://doi.org/10.1016/0009-2614(93)85726-5

[10] Watanabe, T., Ebata, T., Tanabe, S. and Mikami, N. (1996) Size-Selected Vibrational Spectra of Phenol- $\left(\mathrm{H}_{2} \mathrm{O}\right)_{n}(n=1-4)$ Clusters Observed by IR-UV Double Resonance and Stimulated Raman-UV Double Resonance Spectroscopies. The Journal of Chemical Physics, 105, 408-419. https://doi.org/10.1063/1.471917

[11] Hartland, G.V., Henson, B.F., Venturo, V.A. and Felker, P.M. (1992) Ionization-Loss Stimulated Raman Spectroscopy of Jet-Cooled Hydrogen-Bonded Complexes Containing Phenols. The Journal of Physical Chemistry, 96, 1164-1173. https://doi.org/10.1021/j100182a028

[12] Dimitrova, Y. (2004) Ab Initio and DFT Studies of the Vibrational Spectra of Hydrogen-Bonded PhOH... $\left(\mathrm{H}_{2} \mathrm{O}\right)_{4}$ Complexes. Spectrochimica Acta Part A: Molecular and Biomolecular Spectroscopy, 60, 3049-3057.

https://doi.org/10.1016/j.saa.2004.01.026

[13] Shimamori, T. and Fujii, A. (2015) Infrared Spectroscopy of Warm and Neutral Phenol-Water Clusters. The Journal of Physical Chemistry A, 119, 1315-1322. https://doi.org/10.1021/jp512495v

[14] Plokhotnichenko, A.M., Radchenko, E.D., Blagor, Y.P. and Karachevtsev, V.A. (2001) Dimers of Phenol in Argon and Neon Matrices. Low Temperature Physics, 27, 666-675. https://doi.org/10.1063/1.1399207

[15] Ksiązczak, A. and Anderko, A. (1988) A Chemical Approach to the Prediction of Thermophysical Properties of Associating Compounds. Berichte der Bunsengesellschaft Für Physikalische Chemie, 92, 496-504. https://doi.org/10.1002/bbpc.198800115

[16] Samala, N.R. and Agmon, N. (2017) Structure, Spectroscopy, and Dynamics of the Phenol-(Water $)_{2}$ Cluster at Low and High Temperatures. The Journal of Chemical Physics, 147, Article ID: 234307. https://doi.org/10.1063/1.5006055

[17] Perry, R.H. and Green, D.W. (1999) Perry's Chemical Engineers' Handbook. 7th Edition, McGraw-Hill, New York, NY.

[18] Kašpar, J., Fornasiero, P. and Hickey, N. (2003) Automotive Catalytic Converters: Current Status and Some Perspectives. Catalysis Today, 77, 419-449. https://doi.org/10.1016/S0920-5861(02)00384-X 